\title{
A New Method for Studying the Roadway Stability
}

\author{
Qin Zhongcheng ${ }^{1, \mathrm{a}}$,Wang Shengchao ${ }^{1,2, \mathrm{~b}}, \mathrm{Yu} \mathrm{Xin}^{1}$, Cao Bin $^{1}$ \\ ${ }^{1}$ Key Lab of Mine Hazards Prevention and Control, School of Mining and Safety Engineering, Shandong University of Science \\ and Technology, Qingdao, 266590, China \\ ${ }^{2}$ Xingcun coal mine, Tian'an Mining Group, Qufu, 273100, China \\ a qinzhch@126.com, ${ }^{\mathrm{b}}$ wangshch-118@163.com
}

\begin{abstract}
The effect of 5 factors, including roadway width, height, depth, lateral pressure coefficient and comprehensive stress of surrounding rock on the roadway stability by using the method of orthogonal numerical simulation experiment. The experiment results show that all these factors have an effect on the roadway stability, but the significance is not the same. The numerical simulation experiments reflect the theoretical analysis, which indicates that these methods are highly effective concerning the study on the roadway stability.
\end{abstract}

Keywords - orthogonal experiment; roadway stability; influencing Factors.

\section{I.INTRODUCTION}

The factors influencing the roadway stability majorly come from two aspects: 1) natural conditions which include the burial depth of roadway, the strength of surrounding rock, hydrological environments etc.; 2) mining techniques, involving the roadway cross-section shape, dimensions, roadway arrangement type and supporting method etc.[1].This paper presents a study on the effect of above -mentioned factors on the roadway stability.

The ratio of width and height of rectangular roadway can directly influence the stress state of surrounding rock, and the lateral pressure coefficient has an obvious effect on the distribution of the plastic zone of surrounding rock, and the closer the ratio above and the lateral pressure coefficient, the smaller the stress concentration factor of roadway is[2-3]. From the perspective of KANG Hong-pu[4], the deformation and damage of the ribs of roadway are primarily subjected to the vertical stress, and the deformation and damage of roof and floor are determined by the horizontal stress which is the key factor. In the viewpoint of LI Yan-bin et al.[5], the range of plastic failure zone enlarges and the deformation increases with the increment of the burial depth of roadway. And the vertical stress zone of roof and floor expands, while the core of horizontal stress moves into the deeper rock mass. On the contrary, the horizontal stress zone of ribs expands and the core of vertical stress moves into the deeper rock. JING Hongwen, et al.[6] hold the opinion that the strength of surrounding rock is composed of the peak strength and the residual strength of rock mass. When the residual strength is less than $5 \% \sim 10 \%$ of the peak strength, the plastic zone increases dramatically as the residual strength decreases. This paper shows a comprehensive research concerned with the effect of factors involving roadway width and height, burial depth, lateral pressure coefficient and comprehensive strength of surrounding rock on the roadway stability.

\section{II.THEORETICAL ANALYSIS OF THE ROADWAY STABILITY}

\subsection{Comprehensive strength of surrounding rock}

It is postulated that the roadway has a rectangular section and locates in the flat coal seam, roof and floor are constituted of hard strata like sandstones etc., the rib is coal seam, additionally, there is no geological structures such as fault etc., and the rock (coal) layers are well-integrated.

Comprehensive strength of surrounding rock (using CSSR as abbreviation in the following text) is defined as the overall strength of roof, ribs and floor rock mass of roadway, which reflects the general stability of surrounding rock. Specifically, CSSR is a weighted average of uniaxial compressive strength, tensile strength and shear strength of rock, and its unit is MPa. CSSR is given by

$$
\sigma_{\mathrm{i}}=\boldsymbol{\alpha}^{T} \boldsymbol{A} \boldsymbol{\beta}
$$

Where $\sigma \mathrm{i}$ is CSSR; $\boldsymbol{\alpha}^{T}=\left(a_{1}, a_{2}, a_{3}\right)$ is the weight vector of each strength (uniaxial compressive strength, tensile strength and shear strength) to the overall strength of a single rock layer; $; \boldsymbol{\beta}=\left(b_{1}, b_{2}\right.$, $\left.b_{3}\right)^{\mathrm{T}}$ is the weight vector of each rock layer (roof, rib and floor) to CSSR;

$$
\boldsymbol{A}=\left[\begin{array}{ccc}
\sigma_{\mathrm{c} 1} & \sigma_{\mathrm{c} 2} & \sigma_{\mathrm{c} 3} \\
\sigma_{\mathrm{t} 1} & \sigma_{\mathrm{t} 2} & \sigma_{\mathrm{t} 3} \\
\tau_{1} & \tau_{2} & \tau_{3}
\end{array}\right] \text { is the strength matrix of surrounding rock. }
$$

$\boldsymbol{\alpha}^{\boldsymbol{T}}$ in equation (1) is determined by AHP[7]. Uniaxial compressive strength, tensile strength and shear strength are served as the evaluation indexes of the overall strength of a certain stratum. The hierarchy diagram is shown as Fig.1.

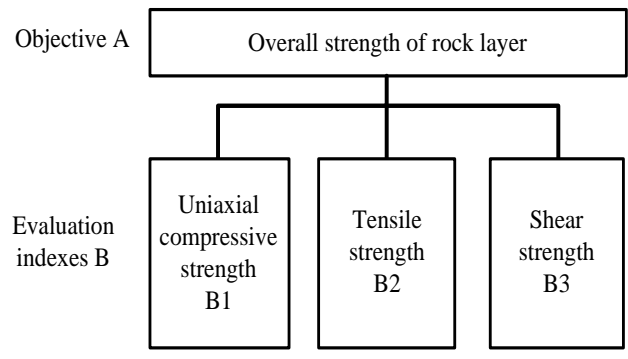

Fig.1 Hierarchy diagram of stratum overall strength 
According to a number of rock mechanical experiments, theoretical analysis and numerical simulation[8-9], formulating 3 order judgment matrix, shown in Eq.(2), of the 3 evaluation indexes mentioned above with reference to the 1 9 scaling law.

$$
p_{A-B}=\left[\begin{array}{ccc}
1 & 6 & 3 \\
1 / 6 & 1 & 1 / 2 \\
1 / 3 & 2 & 1
\end{array}\right]
$$

The maximum characteristic value of Eq.(2) is $\lambda \max =3$. Calculating the feature vector and normalizing it yields:

$$
\alpha^{T}=\left(\begin{array}{lll}
0.661, & 0.111, & 0.222
\end{array}\right)
$$

Since Eq.(2) is a consistent matrix, it surely satisfies the consistency condition. In terms of $\alpha^{T}$, the weight of evaluation index of overall strength of stratum is $\{\mathrm{B} 1: \mathrm{B} 2: \mathrm{B} 3\}=\{0.667: 0.111: 0.222\}$.

The weight vector of each stratum to the overall strength of surrounding rock can also be calculated in the same way as the calculation of $\boldsymbol{\alpha}^{T}$.

$$
\boldsymbol{\beta}=\left(\begin{array}{lll}
0.500, & 0.278, \quad 0.222
\end{array}\right)^{\mathrm{T}}
$$

The weight value of roof, ribs and floor are 50\%, 27.8\%, and $22.2 \%$ respectively.

\subsection{Mechanical analysis of the roof stability}

According to material mechanics, roof can be simplified as uniformly and axially loaded beam fixed at two ends, shown in Fig.2.

Under the co-action of deadweight $\mathrm{q}$ and axial thrust $\mathrm{N}$, the roof beam will be subjected to buckling failure. The approximate differential equation of deflection curve is

$$
\frac{d^{2} \omega}{d x^{2}}=\frac{M_{x}}{E I}
$$

Where $\omega$ is the beam deflection; $M_{x}$ is the resultant moment of a certain section whose outward normal is $x$ axis; $E$ is the elastic modulus; $I$ is the inertia moment of the crosssection to neutral axis.

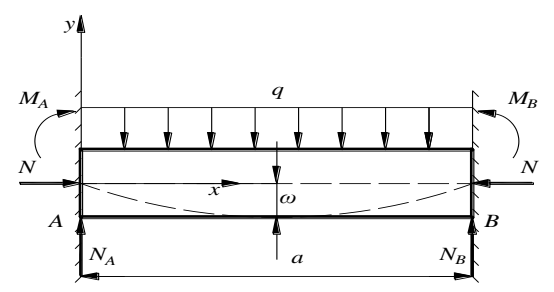

Fig.2 Simplified mechanical model of roof

In which

$$
M_{x}=\frac{q a^{2}}{12}+N \omega-\frac{q x^{2}}{2}+\frac{q a}{2} x
$$

Where a is the span of beam AB.

According to the boundary conditions

$$
\left.\omega\right|_{x=0}=0 ;\left.\quad \frac{d \omega}{d x}\right|_{x=a / 2}=0
$$

Then

$$
\omega=\frac{q\left(\beta^{2} a^{2}-12\right)}{12 N \beta^{2}\left(1+e^{\alpha a}\right)}\left(e^{\beta a}+e^{\beta(a-x)}\right)+\frac{q}{2 N}\left(x^{2}-a x+\frac{12-\beta^{2} a^{2}}{6 \beta^{2}}\right)
$$

According to Eq.(10), the roof stability is not only related to deadweight $q$ and axial thrust $N$, but also concerned with the roof span $a$. While axial thrust $N$ is generated by horizontal stress which has a relation with burial depth $H$ and lateral pressure coefficient $\lambda$, so $H$ and $\lambda$ also have an effect on the roof stability.

\subsection{Mechanical analysis of the rib stability}

Coal seam has characteristic of inhomogeneous and stratified, generally, the strength of roof and floor is harder than the strength of coal seam. For the reason of the cohesion and internal friction angle in the interface between coal seam and roof, floor (using interface for short in the following description) is smaller than those in the coal seam, the coalbody in the stress limiting equilibrium zone $A B C D$ is going to move towards the void after excavating without providing any support. As a result, the movement will lead to the instability of rock mass (coal-body) of ribs[10]. The simplified mechanical model of coal-body in ribs is shown in Fig.3.

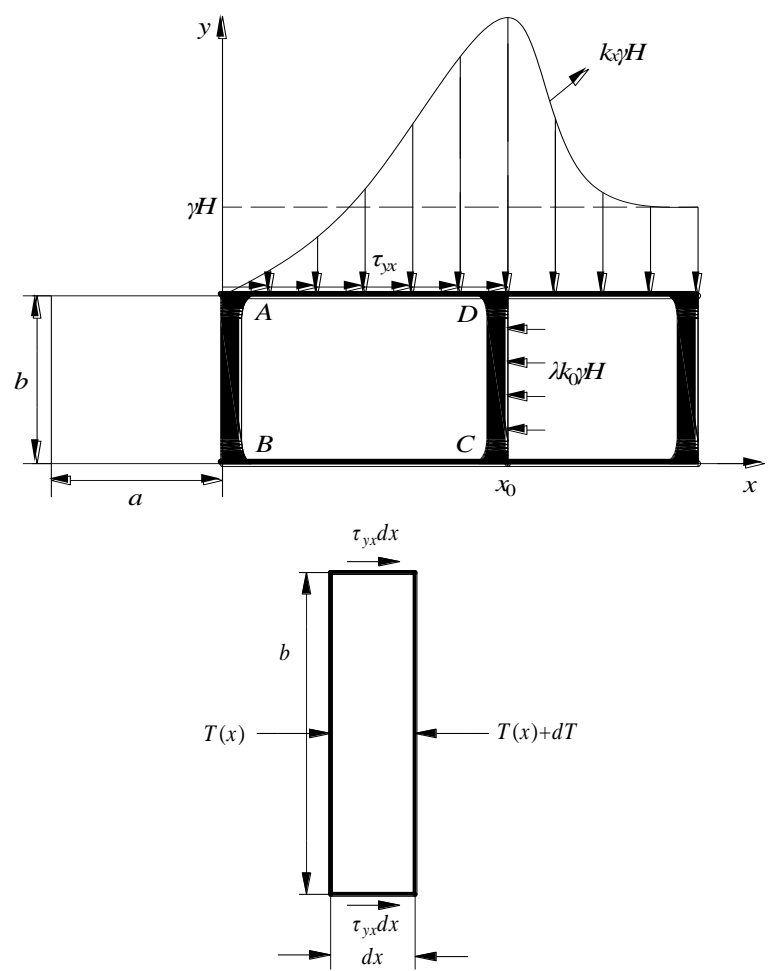

Fig.3 Simplified mechanical model of rib coal body

It is illustrated in Fig.6 that the force analysis of coal unit from stress limiting equilibrium zone $A B C D$.

According to static equilibrium conditions,

$$
T(x)+2 \tau \cdot d x \cdot 1-T(x)-d T(x)=0
$$


Where $T(x)$ is the axial thrust at $x$ of $\mathrm{x}$-coordinate; $\tau$ is shear stress on the interface.

Putting $q=2 \tau$ into Eq.(7) and rearranging yields

$$
q=\frac{d T(x)}{d x}
$$

where $\mathrm{q}$ is shear stress collection degree.

According to Hooke's law

$$
T(x)=b \cdot 1 \cdot \lambda k_{x} \gamma H=b E \frac{d s}{d x}
$$

Where $b$ is the roadway width; $\lambda$ is the lateral pressure coefficient; $k_{x}$ is the stress concentration factor at $x$ of $\mathrm{x}$ coordinate; $\gamma$ is the bulk density of rock; $H$ is the burial depth of roadway; $E$ is the elastic modulus of coal; $s$ is the displacement caused by axial thrust $T(x)$.

According to the boundary conditions

$$
\begin{aligned}
& \left.\frac{d s}{d x}\right|_{x=0}=0 ;\left.\quad \frac{d s}{d x}\right|_{x=x_{0}}=\frac{T\left(x_{0}\right)}{b E} \\
& s=\frac{T\left(x_{0}\right)\left(e^{\alpha x}+e^{-\alpha x}\right)}{b E \alpha\left(e^{\alpha x_{0}}-e^{-\alpha x_{0}}\right)}
\end{aligned}
$$

According to Eq.(11), the ribs' displacement $s$ is not only related to axial thrust $T\left(x_{0}\right)$ and elastic modulus $E$, but also has a relationship with roadway height $b$. The bigger the height $b$ is, the smaller ribs' displacement $s$ will be, on condition that other variables are constant.

\section{III.ORTHOGONAL NUMERICAL SIMULATION EXPERIMENT}

\subsection{Numerical model}

The length, width and height of the 3D numerical model established by using FLAC $^{3 \mathrm{D}}$ are $35 \mathrm{~m}, 8 \mathrm{~m}$ and $35 \mathrm{~m}$ respectively. The rectangular roadway is situated in the middle of the model. Uniformly vertical compressive stress (25.5MPa) is applied to the upper surface of the model. Horizontal compressive stress which varies with the depth is applied to both sides of the model. The horizontal and vertical displacement of the lower surface of the model is fixed. Mohrcoulomb yield criterion is used in the model, as is shown in Fig.4.

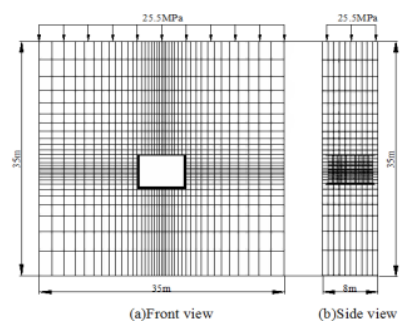

Fig.4 Schematic diagram of the 3D numerical model

\subsection{Evaluation index}

Comprehensive deformation of roadway (CDR) is developed to evaluate the effect of roadway's width and height, burial depth, lateral pressure coefficient and CSSR on the stability of roadway. The smaller the value of CDR is, the less effect on the roadway stability will be. Its unit is $\mathrm{mm}$.

$$
D_{\mathrm{c}}=\boldsymbol{D} \boldsymbol{\beta}
$$

Where $D_{\text {c }}$ is CDR; $\boldsymbol{D}=\left(d_{1}, d_{2}, d_{3}\right)$, the weight vector, displacements of roof, ribs and floor.

\subsection{Orthogonal experiment}

Orthogonal experiment, which is a mathematical statistics method developed to arrange experiment and analyze the data gained from the experiment, by using orthogonal array. Orthogonal experiment has 2 prominent features: 1) different levels of each factor appear in the experiment with the same number of times; 2) different combinations of any levels of any two factors all appear in the experiment. It also has advantages of operation-convenient and efficiency-high etc..

5 factors, including roadway width and height, burial depth, lateral pressure coefficient and CSSR, each of which is chosen 5 different levels, are selecting in the orthogonal experiment to simulate the deformation of roadway. Orthogonal array $\mathrm{L}_{25}\left(5^{6}\right)$ is employed in the experiment. Factors and levels are shown in Table 1, and the experiment scheme is shown in Table 2.

According to Table 2, establishing 25 numerical simulation models, the 5 factors of each model are determined by the corresponding experiment No., and all other conditions are same. CDR is served as the evaluation index, and the experiment results are show in Table 2.

\section{ANALYSIS OF ORTHOGONAL NUMERICAL SIMULATION EXPERIMENT RESULTS}

Extremum difference analysis, which is also known as intuitive analysis, is used in drawing any conclusions of the experiment by analyzing the range and trend chart. Extremum difference analysis is commonly used in orthogonal experiment, since it is straightforward and intuitive According to the results from Table 2, calculating the average and range of different levels of each factor,. The results of the extremum difference analysis are shown in Table 3.

According to the values in the last row of Table 3, arranging them in descending order is $H>\sigma i>\lambda>a>b$, which implies that burial depth is most influential, while CSSR and lateral pressure coefficient are less, and roadway width and height are the least.

According to the results in Table 3, the extremum difference analysis diagram is illustrated in Fig.8, in order to analyze the trend more visually and reflect the effect more vividly.

It can be concluded from Fig.5 that roadway width, height, burial depth, lateral pressure coefficient and CSSR all have an effect on the stability of roadway. However, the significance is not the same. Burial depth and lateral pressure coefficient (when it is less than 1.0) are positively correlated with the roadway stability, while CSSR is negatively correlated with the roadway stability, and there is no obvious correlation between roadway width, height and roadway stability. 
TABLE 1 Factors and levels of orthogonal numerical simulation experiment

\begin{tabular}{cccccc}
\hline \multirow{2}{*}{ Levels } & $\mathrm{A}$ & $\mathrm{B}$ & $\mathrm{C}$ & $\mathrm{D}$ & $\mathrm{E}$ \\
\cline { 2 - 6 } & $a / \mathrm{m}$ & $b / \mathrm{m}$ & $H / \mathrm{m}$ & $\lambda$ & $\sigma_{\mathrm{i}} / \mathrm{MPa}$ \\
\hline 1 & 3 & 2.5 & 200 & 0.3 & 8 \\
2 & 3.5 & 3 & 400 & 0.6 & 28 \\
3 & 4 & 3.5 & 600 & 0.9 & 48 \\
4 & 4.5 & 4 & 800 & 1.2 & 68 \\
5 & 5 & 4.5 & 1000 & 1.5 & 88 \\
\hline
\end{tabular}

TABLE 2 The Scheme for orthogonal experiment

\begin{tabular}{|c|c|c|c|c|c|c|}
\hline \multirow{2}{*}{$\begin{array}{c}\text { Experi-ment } \\
\text { No. }\end{array}$} & \multicolumn{5}{|c|}{ Factors } & \multirow{2}{*}{$\frac{\text { Index }}{D_{\mathrm{c}} / \mathrm{mm}}$} \\
\hline & $a / \mathrm{m}$ & $b / \mathrm{m}$ & $H / \mathrm{m}$ & $\lambda$ & $\sigma_{\mathrm{i}} / \mathrm{MPa}$ & \\
\hline 1 & $3(1)$ & $2.5(1)$ & $200(1)$ & $0.3(1)$ & $8(1)$ & 14.9 \\
\hline 2 & 3 & $3(2)$ & $400(2)$ & $0.6(2)$ & $28(2)$ & 38.3 \\
\hline 3 & 3 & $3.5(3)$ & $600(3)$ & $0.9(3)$ & $48(3)$ & 55.5 \\
\hline 4 & 3 & $4(4)$ & $800(4)$ & $1.2(4)$ & $68(4)$ & 100 \\
\hline 5 & 3 & $4.5(5)$ & $1000(5)$ & $1.5(5)$ & $88(5)$ & 93.5 \\
\hline 6 & $3.5(2)$ & 2.5 & 400 & 0.9 & 68 & 48.1 \\
\hline 7 & 3.5 & 3 & 600 & 1.2 & 88 & 60 \\
\hline 8 & 3.5 & 3.5 & 800 & 1.5 & 8 & 243.2 \\
\hline 9 & 3.5 & 4 & 1000 & 0.3 & 28 & 94.7 \\
\hline 10 & 3.5 & 4.5 & 200 & 0.6 & 48 & 16.4 \\
\hline 11 & $4(3)$ & 2.5 & 600 & 1.5 & 28 & 94.6 \\
\hline 12 & 4 & 3 & 800 & 0.3 & 48 & 79.5 \\
\hline 13 & 4 & 3.5 & 1000 & 0.6 & 68 & 113 \\
\hline 14 & 4 & 4 & 200 & 0.9 & 88 & 37.8 \\
\hline 15 & 4 & 4.5 & 400 & 1.2 & 8 & 76.8 \\
\hline 16 & $4.5(4)$ & 2.5 & 800 & 0.6 & 88 & 95.6 \\
\hline 17 & 4.5 & 3 & 1000 & 0.9 & 8 & 260.5 \\
\hline 18 & 4.5 & 3.5 & 200 & 1.2 & 28 & 29.5 \\
\hline 19 & 4.5 & 4 & 400 & 1.5 & 48 & 59.5 \\
\hline 20 & 4.5 & 4.5 & 600 & 0.3 & 68 & 42.1 \\
\hline 21 & $5(5)$ & 2.5 & 1000 & 1.2 & 48 & 132 \\
\hline 22 & 5 & 3 & 200 & 1.5 & 68 & 32.8 \\
\hline 22 & 5 & 3.5 & 400 & 0.3 & 88 & 40.5 \\
\hline 24 & 5 & 4 & 600 & 0.6 & 8 & 96.8 \\
\hline 25 & 5 & 4.5 & 800 & 0.9 & 28 & 110 \\
\hline
\end{tabular}

Table 3 Extremum difference analysis of comprehensive deformation of roadway

\begin{tabular}{cccccc}
\hline \multirow{2}{*}{ Average } & $\mathrm{A}$ & $\mathrm{B}$ & $\mathrm{C}$ & $\mathrm{D}$ & $\mathrm{E}$ \\
\cline { 2 - 6 } & $a / \mathrm{m}$ & $b / \mathrm{m}$ & $H / \mathrm{m}$ & $\lambda$ & $\sigma_{\mathrm{i}} / \mathrm{MPa}$ \\
\hline 1 & 60.44 & 77.04 & 26.28 & 54.34 & 138.44 \\
2 & 92.48 & 94.22 & 52.64 & 72.02 & 73.42 \\
3 & 80.34 & 96.34 & 69.80 & 102.38 & 68.58 \\
4 & 97.44 & 77.76 & 125.66 & 79.66 & 67.2 \\
5 & 82.42 & 67.76 & 138.74 & 104.72 & 65.48 \\
Range & 37.00 & 28.58 & 112.46 & 50.38 & 72.96 \\
\hline
\end{tabular}




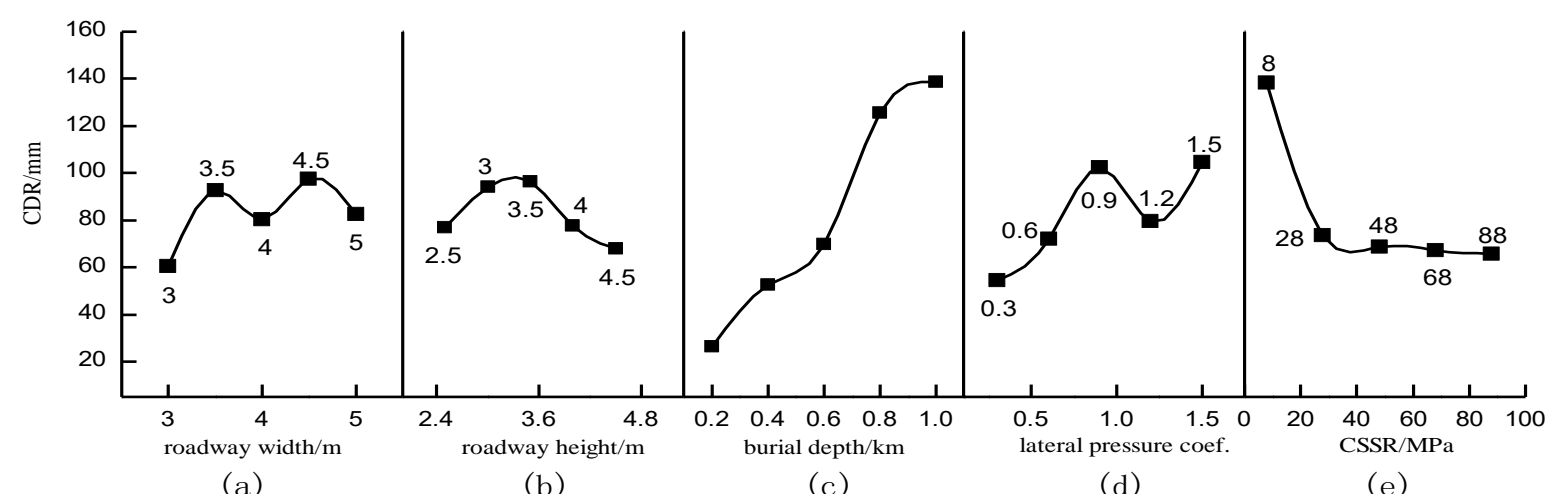

(a)

Fig. 5 The effect of each factor on the roadway stability

CDR is changing so dramatically that it increases by $428 \%$ (from $26.28 \mathrm{~mm}$ to $138.74 \mathrm{~mm}$ ) with the burial depth increases by $400 \%$ (from $200 \mathrm{~m}$ to $1000 \mathrm{~m}$ ). CDR decreases rapidly initially, subsequently changes moderately. CSSR adds from $8 \mathrm{MPa}$ to $10 \mathrm{MPa}$, increased by $250 \%$, and CDR decreases from $138.44 \mathrm{~mm}$ to $73.42 \mathrm{~mm}$, decreased by $47 \%$. CSSR keeps increasing from $28 \mathrm{MPa}$ to $88 \mathrm{MPa}$, increased by $214.3 \%$, CDR decreases from $73.42 \mathrm{~mm}$ to $65.48 \mathrm{~mm}$, only decreased by $10.8 \%$, which implies there is a "inflection point" (about $30 \mathrm{MPa}$ ), when CSSR is less than $30 \mathrm{MPa}$, its influence on CDR is relatively obvious; when CSSR is more than $30 \mathrm{MPa}$, the effect is remarkably weakened.

Additionally, it is trasparent that the burial depth (vertical pressure), which is followed by CSSR and lateral pressure cofficient, is the most important factor on influencing the roadway stability. However, roadway width and height have the least effect on the roadway stabllity.

\section{V.CONCLUSIONS}

1) Comprehensive strength of surrounding rock (CSSR) is put forward on the basis of considering the strength characteristics of roof, ribs and floor

2) Roadway width and height, burial depth, lateral pressure coefficient and CSSR all have an effect on the roadway stability. The sequence of the effect in descending order is burial depth $>$ CSSR > lateral pressure coefficient > roadway width $>$ roadway height.

3) Burial depth is the key factor influencing the roadway stability, and has a negative correlation with roadway stability, i.e. the bigger the burial depth is, the less the roadway stability will be.
4) It provides theoretical basis for roadway bolting support in deep mine, reinforcing surrounding rock by grouting, and the design of roadway cross-section.

\section{ACKNOWLEDGEMENTS}

This paper was supported by the National Natural Science Foundation of China $(51379119,51304126,51109124)$.

\section{REFERENCES}

[1] Zeng Z L. Foadway on factors of laneways distorted and control methods reasonable. Coal Technology, 2008, 27(4) : 141-144.(In Chinese)

[2] Liao X Y, Tan X H, Li Q F. Study on supporting measures and stress distribution of thick coal rectangular roadway. Mineral Engineering Research, 2011, 26(1) : 1-6. (In Chinese)

[3] Li G C, Zhang N, Wang C, et al.. Optimizing the section shape of roadways in high stress ground by numerical simulation. Journal of China University of Mining \& Technology, 2010, 39(5) : 652-658. (In Chinese)

[4] Kang H P. Flac analysis on affecting aactors to rock bolting in gateroads. Chinese Journal of Rock Mechanics and Engineering, 1999, 18(5) : 534-537. (In Chinese)

[5] Li Y B, Yang Y K, Su X G. Study on the stability of surrounding rocks of a coal roadway in different depth. Journal of Taiyuan University of Technology, 2011,42(6) : 603-606. (In Chinese)

[6] Jing H W, Li Y H, Xu G A. Analysis of surrounding rock stability of deeply buried roadways and study on its control techniques. Rock and Soil Mechanics, 2005, 26(6) : 877-880. (In Chinese)

[7] Xu S B. The Principle of Analytical Hierarchy Process. Tianjin: Tianjin Press, 1988. (In Chinese)

[8] Shen M L, Chen J F. Rock Mass Mechanics. Shanghai: Tongji University Press, 2006. (In Chinese)

[9] Tan Y L, Wu S L, Yin Z D. Ground Pressure and Strata Control. Beijing: China Coal Industry Publishing House, 2008. (In Chinese)

[10] Hou C J, Ma N J. Stress in in-seam roadway sides and limit equilibrium zone. Journal of China Coal Society, 1989, 14(4) : 2129. (In Chinese) 